\title{
Impact of Early Adolescent Externalizing Problem Behaviors on Identity Development in Middle to Late Adolescence: A Prospective 7-Year Longitudinal Study
}

\author{
Elisabetta Crocetti • Theo A. Klimstra • \\ William W. Hale III • Hans M. Koot • \\ Wim Meeus
}

Received: 27 November 2012 / Accepted: 28 January 2013/Published online: 6 February 2013

(C) Springer Science+Business Media New York 2013

\begin{abstract}
Adolescents at-risk for problem behaviors can have more difficulties in developing a firm sense of personal identity. Hence the purpose of this prospective longitudinal study was to scrutinize how externalizing problems in early adolescence impact identity development in middle to late adolescence. Participants were 443 (43.12\% female) Dutch adolescents. Teachers rated their externalizing problem behaviors when participants were 11 or 12 years old and their identity formation was studied during five consecutive years (from 14 to 18 years of age). The sample was divided into four groups: boys and girls with a high versus a low-risk for externalizing problem behaviors. Participants completed a self-report measure of identity commitment, in-depth exploration, and reconsideration of commitment. Multi-group Latent Growth Curve and profile stability analyses were used to evaluate identity development across adolescence. Findings indicated that high-risk boys and girls reported a less structured identity, with lower levels of commitment and higher levels of reconsideration of commitment. Since externalizing problems behaviors and lack of a coherent sense of identity might reinforce each other, early intervention for high-risk adolescents might foster positive youth development.
\end{abstract}

E. Crocetti $(\bowtie) \cdot$ W. W. Hale III $\cdot$ W. Meeus

Research Centre Adolescent Development, Utrecht University,

Heidelberglaan 2, 3584 TC Utrecht, The Netherlands

e-mail: e.crocetti@uu.nl

T. A. Klimstra

Catholic University of Leuven, Leuven, Belgium

T. A. Klimstra $\cdot$ W. Meeus

Tilburg University, Tilburg, The Netherlands

H. M. Koot

VU University Amsterdam, Amsterdam, The Netherlands
Keywords Identity - Externalizing problem behaviors . Gender · Longitudinal

\section{Introduction}

Identity formation is the core developmental task of adolescence (Erikson 1950, 1968). Since post-modern societies are seemingly characterized by increasing uncertainty (Baumeister and Muraven 1996; Schwartz 2000), this task is particularly challenging because adolescents have to enact significant choices in multiple domains (e.g., Crocetti et al. 2012). Additionally, a number of factors can hamper adolescent identity formation. In particular, adolescents at a high-risk for problem behaviors may face more difficulties in defining a coherent and stable sense of identity.

Problem behaviors can be differentiated between externalizing and internalizing problems (Achenbach 1978). Specifically, externalizing problem behaviors refer to a cluster of behavior problems (e.g., aggressive and delinquent behaviors) that are manifested in individuals' outward behavior and reflect the youth negatively actingout on their external environment (Achenbach and Edelbrock 1978). Internalizing problem behaviors (e.g., anxiety and depressive symptoms) refer to the individual's internal psychological environment rather than their external environment (Achenbach and Edelbrock 1978). Consistent evidence has revealed straightforward gender differences, with boys more likely to exhibit externalizing problem behaviors and girls more affected by internalizing problem behaviors (e.g., Achenbach 1966; Rescorla et al. 2007).

Up until now, researchers (e.g., Crocetti et al. 2009a) have demonstrated that adolescents at-risk for internalizing problem behaviors have difficulties in developing their 
identity, whereas there is a dearth of studies examining identity formation in adolescents at risk for externalizing problem behaviors. Therefore, the purpose of this longitudinal study was to gain insight into this latter issue by longitudinally analyzing adolescent identity development of boys and girls that had been classified as either at a highrisk or low-risk for externalizing problem behaviors and were compared to one another.

\section{Identity}

\section{Marcia's Identity Status Paradigm}

Erikson's lifespan theory of psychosocial development $(1950,1968)$ was a pioneering contribution to the field of identity studies. The most important empirical elaboration of Erikson's views on identity formation is Marcia's (1966) identity status paradigm. Marcia distinguishes two identity dimensions: exploration (i.e., actively questioning and weighing of various identity alternatives before making decisions about the values, beliefs, and goals that one will pursue) and commitment (i.e., making a relatively firm choice about an identity domain and engaging in significant activities geared toward the implementation of that choice). Using these dimensions, individuals can be classified in one out of four identity statuses: the achievement status, individuals have made a commitment following a period of active exploration; the foreclosure status, adolescents have made a commitment with little or no prior exploration; the moratorium status, adolescents are actively exploring various alternatives and have not yet made a commitment; finally, the diffusion status, adolescents have not engaged in a proactive process of exploration of different alternatives, nor have they made a commitment. Thus, the identity statuses represent distinct ways of dealing with the identity task described by Erikson (1950).

\section{Recent Extensions of the Identity Status Paradigm: The Three-Factor Identity Model}

In the last several decades, various extensions of Marcia's model have been proposed (e.g., Schwartz, 2001). In particular, Meeus, Crocetti, and colleagues (Crocetti et al. 2008b; Meeus et al. 2010), building upon previous studies by Meeus (Meeus 1996; Meeus et al. 1999, 2002), have extended the identity status paradigm by proposing a three factor identity model aimed at capturing the dynamics by which identity is formed and adapted over time. This model takes into account three pivotal identity dimensions. The first identity dimension, commitment, represents enduring choices that individuals have made with regard to various developmental domains and to the self-confidence they derive from these choices; this dimension serves as an indicator of identity consolidation and of successful identity development. The second identity dimension, in-depth exploration, represents the extent to which individuals think actively about the commitments they have enacted (e.g., reflecting on their choices, searching for additional information, talking with others about their commitments). The third and final identity dimension, reconsideration of commitment, represents the comparison of present commitments with possible alternative commitments because the current ones are no longer satisfactory.

This model includes a dual-cycle process (Luyckx et al. 2006; Meeus 2011). In other words, adolescents explore their commitments in-depth and decide whether they provide a good fit with one's overall talents and potentials (which is the identity formation and maintenance cycle). If one's current commitments are not satisfying or do not provide a good fit (any longer), they may be reconsidered in favor of other commitments (which is the identity revision cycle). Crocetti et al. (2008a) found that combining levels of adolescent commitment, in-depth exploration, and reconsideration of commitment (by using empiricallybased methods of deriving identity statuses) it was possible to identify not only all four of Marcia's original identity statuses [achievement, foreclosure (relabeled as "closure" or "early closure" by Meeus et al. 2010), moratorium, and diffusion], but also an additional variant of the moratorium status, labeled searching moratorium. This latter status was characterized by the attempt to revise commitments that have been already enacted.

\section{Identity and Problem Behaviors}

\section{Internalizing Problem Behaviors}

Marcia's identity status paradigm has inspired a large amount of studies (for a review, see: Kroger and Marcia 2011), several of which have focused on associations between identity statuses and problem behaviors. However, most of these studies only have examined internalizing problem behaviors, and consistently have demonstrated that adolescents in the high commitment statuses (i.e., achievement and foreclosure) report low levels of anxiety and depression whereas the moratorium status is associated with the highest levels of anxiety and depression (for a review, see: Meeus et al. 1999). Thus, the identity statuses are consistently associated with different levels of internalizing problems.

Similarly, the three identity dimensions of the extended model have been found to be associated meaningfully with various correlates (Crocetti et al. 2008a, b, 2010), and consistent evidence has shed light on interconnections between internalizing problems (i.e., depressive and anxiety symptoms) and identity. Specifically, commitment has 
been found to be associated negatively with internalizing problems, while in-depth exploration and reconsideration of commitment were linked positively to them (Crocetti et al. 2008b, 2010). Analogously, adolescents in the high commitment statuses were characterized by lower levels of internalizing behaviors than adolescents in the moratorium status (Crocetti et al. 2008a). Interestingly, Crocetti et al. (2009a) monitored identity dimensions, across five consecutive years, in adolescents with low versus high anxiety trajectories and found that adolescents with high anxiety levels had more difficulties in dealing with the identity formation task (i.e., their commitment became weaker over time and their uncertainty about commitments was initially higher and even increased during adolescence) than adolescents with low anxiety levels. Overall, this set of evidence suggests that identity and internalizing problem behaviors are interrelated phenomena, with high levels of problems hampering identity formation and identity instability associated with increasing problem behaviors.

\section{Externalizing Problem Behaviors}

Less research has been conducted on the association between identity and externalizing problem behaviors. Furthermore, available studies differ in their focus, with some research focusing on the broad concept of externalizing problem behaviors (e.g., Pace and Zappulla 2011) and other investigations examining specific types of externalizing problem behaviors, such as aggression, delinquency, and substance use (e.g., Schwartz et al. 2010). This heterogeneity across studies makes it difficult to summarize a conclusive pattern of findings.

More specifically, the few studies that have focused on both identity dimensions (i.e., commitment and exploration) and externalizing problem behaviors within Marcia's identity status paradigm have yielded somewhat divergent findings. For instance, Pace and Zappulla (2011) did not find significant correlations between commitment and externalizing problem behaviors in Italian high school students, whereas Schwartz et al. (2010) reported that commitment was related negatively to some externalizing problem behaviors (e.g., illicit drug use), and not others (e.g., unrelated to binge drinking and unsafe sex behavior) in American college students. Similarly, a limited number of studies have addressed associations among identity statuses and substance use. In this respect, studies involving high-school or first-year college students have documented significant differences in substance use among individuals in the various identity statuses (Bishop et al. 1997; Jones and Hartmann 1988; Jones et al. 1989), but they did not report a consistent pattern of differences. Conversely, studies on young adults did not report significant associations between identity statuses and substance use (Frank et al. 1990; Nelson et al. 2010). In sum, research on identity statuses and externalizing problem behaviors is limited and has not revealed a clear pattern. Further, the aforementioned studies were all cross-sectional, arguing for the need for further clarifying studies conducted with a longitudinal approach (Schwartz 2005).

Research conducted with the three-factor identity model (Crocetti et al. 2008b; Meeus et al. 2010) has provided some evidence useful to unravel interconnections between identity and externalizing problem behaviors in early and middle adolescence. In particular, cross-sectional studies have shown that only reconsideration of commitment was related significantly and positively to delinquency (Crocetti et al. 2008b) and adolescents in the moratorium status reported levels of direct aggression higher than those displayed by their peers in any other identity status (Crocetti et al. 2008a). Furthermore, Klimstra et al. (2011) examined identity formation in juvenile delinquent boys residing in a penitentiary youth institution. They found that these boys differed significantly in identity processes (i.e., juvenile delinquents reported lower commitment and higher reconsideration of commitment) and statuses (i.e., juvenile delinquents were underrepresented in the achievement status, and often displayed the negative side of moratorium, as they were overrepresented in the maladaptive moratorium status) from both male clinically referred youth and male adolescents from the general population. Finally, in a longitudinal study, Meeus et al. (2012) found that early and middle adolescents in the moratorium and diffusion statuses reported higher levels of delinquency than their counterparts in the achievement and early closure statuses. Taken together, this set of evidence suggests that a condition of low commitment and high reconsideration of commitment is intertwined with externalizing problem behaviors.

\section{The Present Study}

In the current longitudinal study we sought to shed light on an issue that has remained uncovered in the extant literature. That is, to what extent might early adolescent externalizing problem behaviors hamper identity formation in middle to late adolescence? In order to address this question, we examined whether teacher rated risk for externalizing problems at the ages of 11 or 12 predicted adolescent identity formation between the ages of 14-18. In light of the limited literature on identity and externalizing problem behaviors, in this study we focused on externalizing problem behaviors as a whole (Achenbach and Edelbrock 1978). Furthermore, given that boys consistently show more externalizing problem behaviors than girls (e.g., Bongers et al. 2003; Rescorla et al. 2007), possible gender differences also were taken into account. 
It is well established that an early history of externalizing behaviors predicts later disruptive behaviors, mood and anxiety problems, and substance use and abuse (e.g., Broidy et al. 2003; Odgers et al. 2008; Reef et al. 2011; Simonoff et al. 2004; Zoccolillo 1992). Interestingly, in a longitudinal study on developmental trajectories of boys' and girls' externalizing problem behaviors and their association with later outcomes Miller et al. (2010) found that although differences were evident in the proportion of boys and girls in some developmental trajectories (i.e., girls were more represented than boys in the no problem group whereas boys were overrepresented in the chronic problem group) gender did not moderate the effect of trajectory membership. Thus, the risks on subsequent depression, partner violence, and risky sexual behavior resulting from the delinquency trajectories were the same for both boys and girls.

In this study, we first examined whether the negative impact of early adolescent externalizing problem behaviors also applied to identity formation. We examined identity development trajectories with the three-dimensional model proposed by Meeus, Crocetti, and collaborators (e.g., Crocetti et al. 2008b; Meeus et al. 2010). We focused on overall identity obtained from the combination of one ideological domain (education) and one interpersonal domain (friendship). We selected these domains because the literature indicates that, for adolescents, education and friendships are among the most important identity domains (e.g., Bosma 1985). When unraveling developmental patterns, it is necessary to examine both inter-individual and intra-individual change (e.g., Block and Robins 1993). Specifically, inter-individual development can be assessed as mean-level change, that is, analyzing whether mean scores of populations or subgroups within populations are different in level and rate of change (e.g., Duncan et al. 1999). Intra-individual change may be captured by profile stability, that is, the stability of a person's configuration of identity dimensions over time (e.g., Roberts et al. 2001). High levels of profile stability indicate that an adolescent's identity profile is well-organized and hence is an indicator of maturation. Given the specific information that both types of change (i.e., mean-level change and profile stability) provide, their integration is meaningful for a better understanding of adolescent development (e.g., Klimstra et al. 2009).

We hypothesized that early adolescents at high-risk for externalizing problem behaviors might have more difficulties in enacting a firm sense of identity later on. Our hypothesis was based on the assumption that an early history of problem behaviors can "attract" a constellation of negative experiences that reduce opportunities of identity formation and consolidation. In particular, externalizing problem behaviors are associated with negative interactions with parents, siblings, and peers (e.g., Buist et al. 2004, 2013; Dodge et al. 2003; Kim et al. 1999; Sturaro et al. 2011) and school underachievement (e.g., Hinshaw 1992). The lack of warm relationships and positive school experiences might strongly limit adolescents' opportunities for identity exploration and commitment in the educational and interpersonal domains (Oyserman and Destin 2010), which represent two key identity domains in this developmental period (Bosma 1985; Crocetti et al. 2012).

More specifically, building on these considerations and in light of previous research conducted with the threedimensional identity model (Crocetti et al. 2008a, b; Klimstra et al. 2011; Meeus et al. 2012), we expected, in terms of mean levels, that adolescents who run a high-risk for externalizing behaviors in early adolescence to have lower levels of commitment and higher levels of reconsideration when compared to adolescents who run a low-risk for externalizing problem behaviors in middle adolescence. We also expected that identity difficulties would exacerbate over middle-to-late adolescence in youth at high-risk for externalizing problem behaviors, which would be reflected by a decrease in levels of commitment and an increase in levels of reconsideration of commitment across time. Regarding intra-individual change, the problem of establishing a firm sense of identity for high-risk adolescents also might be reflected by a relatively unstable identity profile. That is, we expected high-risk adolescents to exhibit lower levels of intra-individual stability (i.e., profile stability of the three identity dimensions). We explored whether the expected pattern of findings applied to the same extent to boys and girls, in order to clarify the possible moderating role of gender.

\section{Method}

\section{Participants}

Data were drawn from the ongoing longitudinal RADAR study (Research on Adolescent Development and Relationships). The RADAR study is a population-based prospective cohort study conducted in the Netherlands aimed at examining normal and abnormal behavioral adolescent development. Because of a specific focus on normal and abnormal development, a dual selection procedure was used to oversample adolescents at high-risk for externalizing problem behaviors. In a first step, teacher ratings of behavior problems were collected through the Teacher's Report Form (TRF; Achenbach 1991). For this purpose, 5,150 early adolescents were assessed when they were 11 or 12 years old. According to the TRF scores, adolescents were assigned to a high-risk or low-risk group. In a second 
step, early adolescents that fit with the project inclusion criteria (e.g., possibility to include the full family, fluency in the Dutch language reported by each family member) were further selected and invited to participate in the study. The object of this second step was to obtain a study sample of approximately 300 low-risk and 200 high-risk participants. Detailed information on the overall sampling are reported in van Lier et al. (2008).

Participants for the current study were 443 Dutch adolescents. The sample was divided into four groups: highrisk for externalizing problem behaviors boys $(n=99)$; low-risk boys $(n=153)$; high-risk girls $(n=76)$; and lowrisk girls $(n=115)$. All participants were Dutch and attended high-school. Most $(n=396 ; 89.4 \%)$ of the adolescents reported their families to have a medium or high socio-economic status. Teachers rated children's externalizing problem behaviors at ages 11 or 12 , and identity formation was studied during five consecutive years from age $14\left(S D_{\text {age }}=0.45\right)$ until age 18.

Missing value analyses indicated that $27.3 \%$ of the participants did not reported on some items. The range of missing items varied from 1.5 to $40 \%$ across the waves. Missing item values were estimated in SPSS using the EM-procedure. Little's (1988) Missing Completely at Random (MCAR) test produced a statistically non-significant value of $\chi^{2} / d f=0.98(p=.77)$, which reveals a very good fit between sample scores with and without imputations, suggesting that data were likely missing at-random.

\section{Procedure}

Before the start of the study, adolescents and their parents received written information about the study and parents provided written informed consent. Within each year of the study, trained research assistants made appointments for annual home visits. During these visits, participants completed a battery of questionnaires. Research assistants provided verbal instructions in addition to the written instructions that accompanied the questionnaires. The RADAR study has been approved by the Medical Ethical Committee of Utrecht University Medical Centre (the Netherlands), and all participants and their parents provided informed consent.

Measure

\section{Identity}

Identity commitment, in-depth exploration, and reconsideration of commitment were measured using the UtrechtManagement of Identity Commitments Scale (U-MICS; Crocetti et al. 2008b). The U-MICS consists of 26 items with a response scale ranging from 1 (completely untrue) to
5 (completely true). Thirteen items index the target processes in one ideological domain (education), and 13 items index the target processes in one interpersonal domain (friendship). Sample items include: "My education/best friend gives me certainty in life" (commitment; 10 items), "I think a lot about my education/best friend" (in-depth exploration; 10 items), and "I often think it would be better to try to find a different education/best friend" (reconsideration of commitment; 6 items). Although the U-MICS assesses identity in different domains, the instrument can be employed to measure overall identity, summing responses across the two domains. Indeed, by means of confirmatory factor analyses, Crocetti et al. (2008b, 2010) demonstrated the internal validity of the three-dimensional model across domains in different gender, age, and ethnic groups. In the present study Cronbach's alphas of the U-MICS subscales ranged across waves from .89 to .91 for commitment, from .84 to .85 for in-depth exploration, and from .81 to .84 for reconsideration of commitment, respectively.

\section{Externalizing Problem Behaviors}

Externalizing problems were evaluated by means of the Teacher's Report Form Externalizing behavior scale (TRF/ 6-18; Achenbach 1991; for the Dutch version see Verhulst et al. 1997). Items refer to externalizing problems that include aggressive and delinquent behaviors. Sample items comprise: "This child attacks people", "This child destroys others' things", and "This child breaks rules". Teachers responded to each item using a 3-point Likert scale: 0 (never), 1 (sometimes), and 2 (frequently applicable), and referring to the previous 2 months. Verhulst et al. (1997) have demonstrated good reliability and validity of the Dutch version of the TRF (see Ivanova et al. 2007, for a test of TRF factorial validity in 20 societies). Participants were classified as either having a score at or above (i.e., high-risk group) the borderline clinical range of TRF externalizing or having a score below the cut-off (i.e., low-risk group).

\section{Data Analysis Strategy}

In order to reach the goals of this study we examined two indices of identity development (i.e., mean-level change and profile stability).

\section{Mean-Level Change}

To model longitudinal variations in identity dimensions we conducted Latent Growth Curve analyses (LGC; e.g., Duncan et al. 1999) in Mplus 4.0 (Muthén and Muthén 2006) with Maximum Likelihood Robust estimation 
(MLR; Satorra and Bentler 1994). LGC provides mean levels (i.e., intercepts) and mean change rates (i.e., slopes) that are based on individual growth trajectories of all participants.

To determine what shape of growth characterized our data best, we first tested various types of latent growth curves, that is: no growth, linear growth, and quadratic growth. The model fit was examined relying on various indices (Kline 2011): the ratio of the Chi square statistic to the degrees of freedom $\left(\chi^{2} / d f\right)$ which should be less than 3 , the Goodness of Fit Index (GFI) and the Tucker-Lewis Index (TLI) which should exceed .95 (Hu and Bentler 1999), and the Root Mean Square Error of Approximation (RMSEA) which should be less than .08 , with values less than .05 representing a good fit (Browne and Cudeck 1993). In order to determine significant differences between models at least two out of these three criteria had to be matched: $\Delta \chi^{2}$ significant at $p<.05$ (Satorra and Bentler 2001), $\Delta$ CFI $>.01$ (Cheung and Rensvold 2002), and $\Delta$ TLI $>.02$ (Vandenberg and Lance 2000).

We then used the unconstrained models to determine growth in the various groups (i.e., high-risk versus low-risk boys and girls). Next, we examined whether there were significant differences in growth estimates (i.e., means of intercepts and slopes) in these groups. For this purpose, we compared the fit of unconstrained models (i.e., models in which these growth estimates were freely estimated) to the fit of constrained models (i.e., models in which these growth estimates were constrained to be equal for the different groups). If a model in which a specific growth estimate was constrained to be equal for two groups (i.e., a constrained model) yielded a significantly worse fit than a model in which the same growth estimate was freely estimated for two groups (i.e., an unconstrained model), we concluded that there was a significant difference in that specific growth estimate.

\section{Profile Stability}

Profile stability was assessed with $q$-correlations (e.g., Block 1971). A $q$-correlation was calculated for each individual separately, by correlating a rank-ordered set of identity dimensions at one measurement occasion (e.g., T1) with a rank-ordered set of the same identity dimensions at the subsequent measurement occasion (e.g., T2). The higher the $q$-correlation, the more stable a constellation of identity dimensions within a person is (e.g., Roberts et al. 2001). To test whether the four groups showed different levels of profile stability over time we conducted a Repeated Measures Analysis of Variance in which profile stability across waves was the within-subjects factor and classification in the four groups was the between-subjects factor.

\section{Results}

\section{Mean-Level Change}

Means and standard deviations for identity dimensions computed across waves in the total sample and for the four groups separately are reported in Table 1. Results of LGC analyses performed for the total sample indicated that curvilinear growth (i.e., a combination of linear and curvilinear slopes) was the best fitting and more parsimonious model for each identity dimension (see Table 2).

After this we proceeded to multi-group models with four groups (i.e., high-risk versus low-risk boys and girls). For commitment, the unconstrained model $\left(\chi^{2}=38.88\right.$, $d f=30 ; \chi^{2} / d f=1.30 ;$ CFI $=.98 ;$ TLI $=.98 ;$ RMSEA $=$ $.05)$ in which all parameters were free to vary across groups was significantly different $\left(\Delta \chi^{2} \quad(9)=, \quad p=.02\right.$; $\Delta \mathrm{CFI}=.01 ; \Delta \mathrm{TLI}=.02)$ from the constrained model $\left(\chi^{2}=57.10, d f=39 ; \chi^{2} / d f=1.46 ;\right.$ CFI $=.97 ;$ TLI $=$ .96 ; RMSEA $=.07)$ in which all the parameters were fixed across groups. Similar results applied also to in-depth exploration (unconstrained model: $\chi^{2}=58.59, d f=30$; $\chi^{2} / d f=1.95 ; \quad$ CFI $=.94 ; \quad$ TLI $=.92 ; \quad$ RMSEA $=.09 ;$ constrained model: $\chi^{2}=89.82, d f=39 ; \chi^{2} / d f=2.30$; $\mathrm{CFI}=.89 ; \mathrm{TLI}=.89 ; \mathrm{RMSEA}=.11$; model comparisons: $\left.\Delta \chi^{2}(9)=22.69, p<.01 ; \Delta \mathrm{CFI}=.05 ; \Delta \mathrm{TLI}=.03\right)$ and reconsideration of commitment (unconstrained model: $\chi^{2}=42.75, d f=30 ; \chi^{2} / d f=1.43 ;$ CFI $=.96 ;$ TLI $=.95 ;$ RMSEA $=.06$; constrained model: $\chi^{2}=62.27, d f=39$; $\chi^{2} / d f=1.60 ; \quad$ CFI $=.93 ; \quad$ TLI $=.93 ; \quad$ RMSEA $=.07 ;$ model comparisons: $\Delta \chi^{2}(9)=19.72, p<.05 ; \Delta \mathrm{CFI}=$ $.03 ; \Delta \mathrm{TLI}=.02$ ). Thus, we performed pairwise comparisons in order to test which specific growth factors differed across groups for each identity dimension. These comparisons are reported in Table 3 and estimated growth curves for each identity dimensions across groups are presented in Fig. 1.

With regard to commitment, high-risk boys reported significantly lower initial levels of commitment than lowrisk girls, while significant differences in growth factors (i.e., linear and quadratic slopes) appeared between lowrisk boys and high-risk girls. As displayed in Fig. 1, lowrisk boys tend to have higher levels of commitment throughout adolescence, whereas high-risk girls report decreasing levels of commitment.

Regarding in-depth exploration, low-risk boys reported the lowest initial levels of in-depth exploration, whereas high-risk girls reported the highest level, and high-risk boys and low-risk girls scored intermediately. Differences on growth factors were less pronounced, with only a significant difference on the quadratic slope between high-risk boys and low-risk girls. Specifically, both groups reported a decrease in in-depth exploration from $\mathrm{T} 1$ to $\mathrm{T} 3$ that was 
Table 1 Observed means and standard deviations of identity dimensions

\begin{tabular}{|c|c|c|c|c|c|c|c|c|c|c|}
\hline & \multicolumn{2}{|l|}{$\mathrm{T} 1$} & \multicolumn{2}{|l|}{$\mathrm{T} 2$} & \multicolumn{2}{|l|}{$\mathrm{T} 3$} & \multicolumn{2}{|l|}{$\mathrm{T} 4$} & \multicolumn{2}{|l|}{ T5 } \\
\hline & $M$ & $S D$ & $M$ & $S D$ & $M$ & $S D$ & $M$ & $S D$ & $M$ & $S D$ \\
\hline \multicolumn{11}{|l|}{ Total sample } \\
\hline Commitment & 3.66 & .62 & 3.62 & .64 & 3.61 & .64 & 3.63 & .68 & 3.57 & .70 \\
\hline In-depth exploration & 3.24 & .62 & 3.24 & .63 & 3.18 & .64 & 3.25 & .64 & 3.21 & .63 \\
\hline Reconsideration of commitment & 1.86 & .74 & 1.83 & .70 & 1.90 & .72 & 1.89 & .75 & 2.01 & .74 \\
\hline \multicolumn{11}{|l|}{ High-risk boys } \\
\hline Commitment & 3.54 & .63 & 3.49 & .71 & 3.48 & .76 & 3.54 & .68 & 3.53 & .76 \\
\hline In-depth exploration & 3.22 & .68 & 3.19 & .68 & 3.08 & .79 & 3.26 & .75 & 3.32 & .74 \\
\hline Reconsideration of commitment & 2.02 & .79 & 1.99 & .81 & 2.09 & .82 & 1.94 & .81 & 2.10 & .80 \\
\hline \multicolumn{11}{|l|}{ Low-risk boys } \\
\hline Commitment & 3.66 & .58 & 3.66 & .59 & 3.66 & .58 & 3.73 & .54 & 3.64 & .59 \\
\hline In-depth exploration & 3.13 & .57 & 3.12 & .58 & 3.15 & .61 & 3.16 & .65 & 3.10 & .60 \\
\hline Reconsideration of commitment & 1.82 & .72 & 1.82 & .69 & 1.86 & .71 & 1.87 & .71 & 1.98 & .65 \\
\hline \multicolumn{11}{|l|}{ High-risk girls } \\
\hline Commitment & 3.68 & .64 & 3.67 & .69 & 3.51 & .65 & 3.50 & .79 & 3.54 & .67 \\
\hline In-depth exploration & 3.43 & .59 & 3.45 & .63 & 3.31 & .55 & 3.34 & .61 & 3.38 & .53 \\
\hline Reconsideration of commitment & 2.01 & .87 & 1.81 & .66 & 1.85 & .64 & 2.05 & .79 & 2.11 & .82 \\
\hline \multicolumn{11}{|l|}{ Low-risk girls } \\
\hline Commitment & 3.75 & .64 & 3.67 & .60 & 3.70 & .59 & 3.66 & .73 & 3.55 & .78 \\
\hline In-depth exploration & 3.27 & .64 & 3.32 & .60 & 3.23 & .58 & 3.29 & .53 & 3.15 & .60 \\
\hline Reconsideration of commitment & 1.68 & .60 & 1.70 & .63 & 1.82 & .66 & 1.78 & .73 & 1.91 & .73 \\
\hline
\end{tabular}

Table 2 Model comparisons

\begin{tabular}{|c|c|c|c|c|c|c|c|c|c|c|c|c|c|}
\hline & \multicolumn{5}{|c|}{ Linear model } & \multicolumn{5}{|c|}{ Quadratic model } & \multicolumn{3}{|l|}{ Model difference } \\
\hline & $\overline{\chi^{2}}$ & $d f$ & $\mathrm{CFI}$ & TLI & RMSEA & $\chi^{2}$ & $d f$ & CFI & TLI & RMSEA & $\Delta \chi^{2}(\Delta d f)$ & $\Delta \mathrm{CFI}$ & $\Delta \mathrm{TLI}$ \\
\hline Commitment & 19.849 & 10 & .977 & .977 & .047 & 6.552 & 6 & .999 & .998 & .014 & $13.297(4), p<.05$ & .022 & .021 \\
\hline In-depth exploration & 39.976 & 10 & .928 & .928 & .082 & 9.080 & 6 & .993 & .988 & .034 & $30.896(4), p<.001$ & .065 & .060 \\
\hline $\begin{array}{l}\text { Reconsideration of } \\
\text { commitment }\end{array}$ & 24.890 & 10 & .949 & .949 & .058 & 10.001 & 6 & .986 & .977 & .039 & $14.889(4), p<.05$ & .037 & .028 \\
\hline
\end{tabular}

$\chi^{2}$ Chi square, $d f$ degrees of freedom, CFI Comparative Fit Index, TLI Tucker-Lewis Index, RMSEA root mean square

followed by an increase in exploration, however this latter increase was sharper for boys.

Regarding reconsideration of commitment, low-risk girls reported the lowest initial level, whereas high-risk boys scored the highest and the other two groups reported intermediate scores. Significant variations in growth factors (detected both in linear and in quadratic slopes) differed between low versus high-risk girls. As shown in Fig. 1, low-risk girls showed very low initial levels of reconsideration that increased linearly throughout adolescence, while high-risk girls exhibited higher initial levels of reconsideration that remained higher throughout the entire course of adolescence but were characterized by more variation, with a decrease between $\mathrm{T} 1$ and $\mathrm{T} 2$, followed by an increase, that was particularly sharp between $\mathrm{T} 3$ and $\mathrm{T} 5$.

Profile Stability

Profile stability was computed for the total sample as well as for the four groups (see Table 4). Results of the repeated-measures analysis of variance indicated significant differences among the four groups in profile stability over time $\left(F(3,423)=9.06, p<.001, \eta^{2}=.06\right)$. Pairwise comparisons (see Table 4) revealed that high-risk boys reported the lowest level whereas low-risk girls reported the highest level of profile stability across time (estimated 
Table 3 Growth factors for latent growth curve models of identity dimensions

\begin{tabular}{|c|c|c|c|c|c|}
\hline & \multirow{2}{*}{$\begin{array}{l}\text { Total sample } \\
M\left(\sigma^{2}\right)\end{array}$} & \multicolumn{4}{|l|}{ Group comparisons } \\
\hline & & $\begin{array}{l}\text { High-risk boys } \\
M\left(\sigma^{2}\right)\end{array}$ & $\begin{array}{l}\text { Low-risk boys } \\
M\left(\sigma^{2}\right)\end{array}$ & $\begin{array}{l}\text { High-risk girls } \\
M\left(\sigma^{2}\right)\end{array}$ & $\begin{array}{l}\text { Low-risk girls } \\
M\left(\sigma^{2}\right)\end{array}$ \\
\hline \multicolumn{6}{|l|}{ Commitment } \\
\hline Intercept & $3.65(0.21)^{* * *}$ & $3.53(0.12)^{* * *, \mathrm{a}}$ & $3.64(0.17)^{* * *, a b}$ & $3.70(0.29)^{* * *, a b}$ & $3.73(0.30)^{* * *, b}$ \\
\hline Linear Slope & $-0.01(0.07)$ & $-0.02(0.01)^{\mathrm{ab}}$ & $0.05(0.06)^{\mathrm{b}}$ & $-0.12(0.18)^{\mathrm{a}}$ & $-0.02(0.02)^{\mathrm{ab}}$ \\
\hline Quadratic Slope & $0.00(0.01)$ & $0.01(0.00)^{\mathrm{ab}}$ & $-0.01(0.01)^{\mathrm{a}}$ & $0.02(0.01)^{\mathrm{b}}$ & $-0.01(0.00)^{\mathrm{ab}}$ \\
\hline \multicolumn{6}{|c|}{ In-Depth Exploration } \\
\hline Intercept & $3.24(0.27)^{* * *}$ & $3.23(0.21)^{* * * a \mathrm{ab}}$ & $3.12(0.18)^{* * *, a}$ & $3.43(0.32)^{* * *, \mathrm{c}}$ & $3.27(0.20)^{* * *, b c}$ \\
\hline Linear Slope & $-0.01(0.15)$ & $-0.09(0.01)^{\mathrm{a}}$ & $0.03(0.13)^{\mathrm{a}}$ & $-0.08(0.32)^{\mathrm{a}}$ & $0.06(0.01)^{\mathrm{a}}$ \\
\hline Quadratic Slope & $0.00(0.01)$ & $0.03(0.00)^{\mathrm{b}}$ & $-0.01(0.01)^{\mathrm{ab}}$ & $0.02(0.01)^{\mathrm{ab}}$ & $-0.02(0.00)^{\mathrm{a}}$ \\
\hline \multicolumn{6}{|l|}{ Reconsideration } \\
\hline Intercept & $1.86(0.29)^{* * *}$ & $2.02(0.44)^{* * *, \mathrm{c}}$ & $1.83(0.20)^{* * *, a b}$ & $1.96(0.18)^{* * *, b c}$ & $1.68(0.28)^{* * *, a}$ \\
\hline Linear Slope & $-0.03(0.15)$ & $-0.02(0.24)^{\mathrm{ab}}$ & $-0.02(0.05)^{\mathrm{ab}}$ & $-0.14(0.11)^{\mathrm{a}}$ & $0.04(0.15)^{\mathrm{b}}$ \\
\hline Quadratic Slope & $0.02(0.01)^{*}$ & $0.01(0.01)^{\mathrm{a}, \mathrm{b}}$ & $0.01(0.01)^{\mathrm{a}, \mathrm{b}}$ & $0.05(0.00)^{*, \mathrm{~b}}$ & $0.01(0.01)^{\mathrm{a}}$ \\
\hline
\end{tabular}

$M$ Mean, $\sigma^{2}$ Variance; Within each row, different superscripts indicate significant $(p<.05)$ Tukey post hoc differences among the high versus the low-risk boys and girls

$* p<.05 ; * * p<.01 ; * * * p<.001$

marginal means were .64 and .85 , respectively). Further, within each gender, high-risk adolescents reported significant lower profile stability than their low-risk counterparts (i.e., high-risk boys exhibited lower profile stability than low-risk boys and high-risk girls displayed lower profile stability than low-risk girls).

\section{Discussion}

Identity formation is the most important developmental task of adolescence and the extent to which young people endorse meaningful commitments in relevant domains impact their capacities of properly facing adult developmental tasks (Erikson 1950, 1968). Thus, resolving the identity formation task represents a great challenge. Therefore, a major priority in the scientific agenda of social scientists is to improve the understanding of which conditions can facilitate or, on the contrary, obstruct adolescents' pursuit of a clear sense of themselves.

In this study, we focused on the potential detrimental role that problem behaviors can have on identity development. In particular, we sought to shed light on identity paths of both boy and girl early adolescents with either a low-risk or high-risk for externalizing problem behaviors. The distinction of the low-risk and high-risk groups was based on teacher reports provided when the respondents were 11 or 12 years old. Then, youth were followed over the course of adolescence from 14 to 18 years old, with a five-wave longitudinal design with annual assessments, to monitor their identity development. Findings regarding both inter-individual and intra-individual changes revealed an interesting pattern of differences among boys and girls with a low versus a high-risk for externalizing problem behaviors.

\section{Early Adolescent Externalizing Problem Behaviors Predicting Identity Formation at Age 14}

First, we found that early adolescents who had been rated as a low-risk versus a high-risk for externalizing problem behaviors by their teachers reported significant differences in identity at age 14. Specifically, high-risk boys exhibited the most disorganized identity: they displayed a combination of low commitment, medium in-depth exploration, and high reconsideration of commitment that is typical of the moratorium status. This finding is consistent with previous research conducted with the three-factor identity dimensional model that has indicated that reconsideration of commitment was related to delinquency (Crocetti et al. 2008b) and that adolescents in the moratorium status reported more direct aggression (Crocetti et al. 2008a, b) and delinquency (Meeus et al. 2012) than their peers in the high commitment statuses. Similarly, Klimstra et al. (2011) found that juvenile delinquent boys residing in a youth penitentiary institution reported lower commitment and higher reconsideration of commitment than both clinically referred male youth and male adolescents from the general population.

Thus, at age 14, at-risk boys were behind their peers in terms of identity formation. This could be due both to the negative impact of problem behaviors and to gender differences in identity. Indeed, girls seem to be ahead of boys 

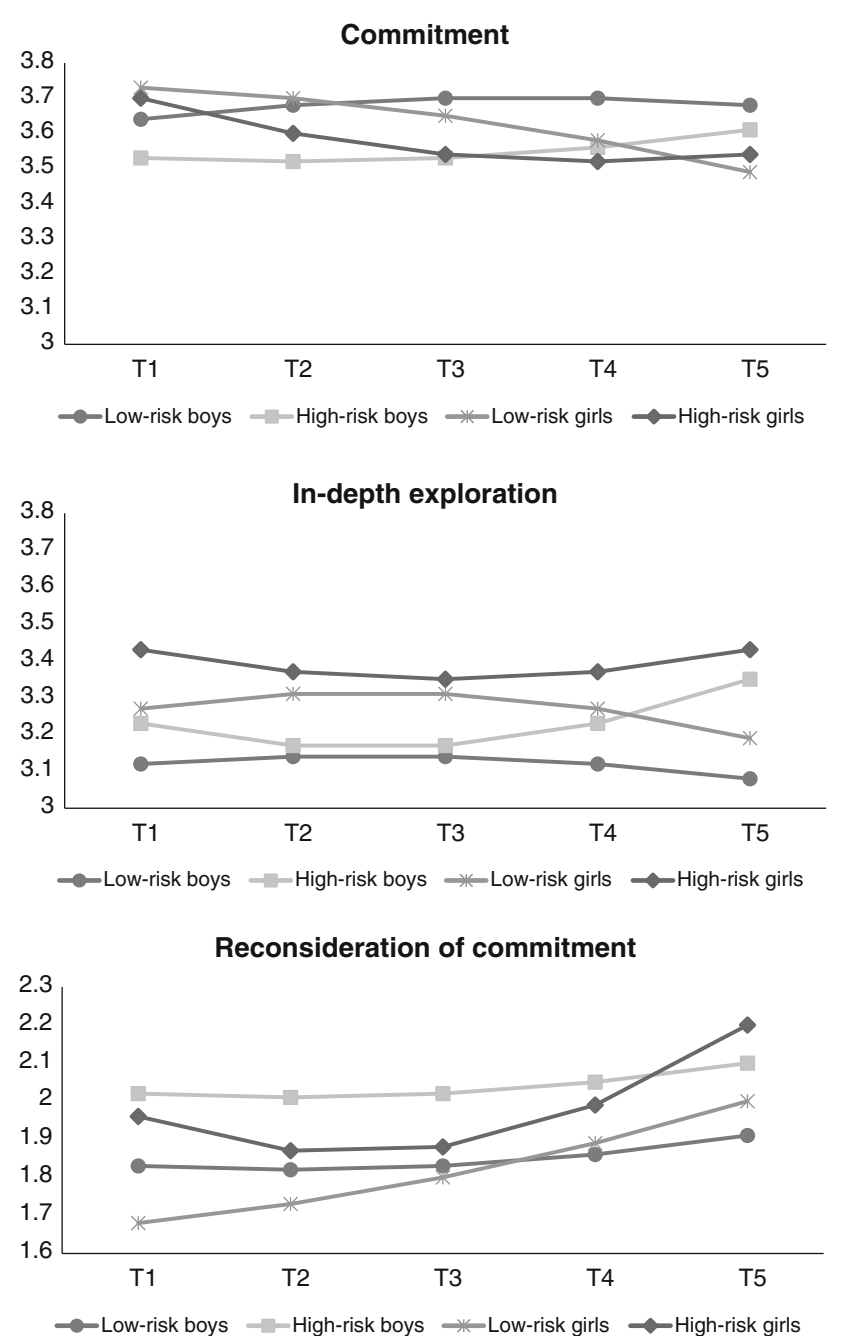

Fig. 1 Estimated growth of identity dimensions in boys and girls with a low- versus a high-risk of externalizing problem behaviors

Table 4 Profile stability of identity dimensions

\begin{tabular}{lccccl}
\hline & T1-T2 & T2-T3 & T3-T4 & T4-T5 & $\begin{array}{l}\text { Estimated } \\
\text { marginal } \\
\text { means }\end{array}$ \\
\hline Total sample & .77 & .79 & .77 & .78 & \\
Group comparisons & & & & & \\
High-risk boys & .66 & .64 & .65 & .63 & $.64^{\mathrm{a}}$ \\
Low-risk boys & .78 & .86 & .81 & .83 & $.82^{\mathrm{cd}}$ \\
High-risk girls & .73 & .78 & .77 & .76 & $.76^{\mathrm{bc}}$ \\
Low-risk girls & .89 & .87 & .82 & .84 & $.85^{\mathrm{d}}$ \\
\hline
\end{tabular}

In the last column, different superscripts indicate significant $(p<.05)$ differences among estimated marginal means computed for the four groups

in identity formation in early to middle adolescence, with boys catching up again in middle to late adolescence (Klimstra et al. 2010). In line with this gender difference, we found that at age 14 low-risk girls were more committed and less engaged in reconsideration of commitment, revealing a condition of higher identity certainty. Low-risk boys and high-risk girls reported an intermediate profile, suggesting that both a low risk of problem behaviors and a being a female played a protective role.

\section{Early Adolescent Externalizing Problem Behavior Predicting Identity Formation in Middle to Late Adolescence}

By means of a five-wave longitudinal design, we also documented specific identity paths over the course of adolescence. We found that identity development was captured by curvilinear growth models (i.e., a combination of linear and quadratic slopes; see Table 1). We also detected significant subgroup differences in identity growth indices. In particular, the main differences occurred in commitment slopes of low-risk boys and high-risk girls and in reconsideration of commitment slopes of the low versus the high-risk girls. Results indicated that, over the course of adolescence, high-risk girls displayed a decrease in commitment, particularly sharp at the beginning of adolescence, which was combined with an increase in reconsideration that was the most pronounced toward the end of adolescence.

These differences between the low-risk and the high-risk boy and girl adolescents reflect inter-individual patterns (Duncan et al. 1999). Analysis of intra-individual change may provide further insight into the phenomenon under investigation. Findings on profile stability, which indicates the stability of the rank order of identity dimensions within each person (Block 1971; Roberts et al. 2001), indicated that high-risk boys reported the lowest stability, whereas low-risk girls the highest. This finding suggests that, for high-risk boys, identity is less consistently organized. Therefore, they may experience more identity distress than low-risk girls. Furthermore, within each gender, high-risk adolescents reported significantly lower profile stability than their low-risk counterparts.

Taken together, these findings highlight that, over the course of adolescence, identity formation is particularly challenging for high-risk boys and girls. Since externalizing problem behaviors are more common among boys than among girls (e.g., Bongers et al. 2003; Moffitt 1993; Rescorla et al. 2007), some further considerations about what happens in high-risk girls are worthy of attention. High-risk girls may perceive themselves to deviate from what is expected to be typical of the feminine role. Therefore, girls with a high-risk of externalizing problems could perceive themselves to be less socially accepted. This might hamper their identity formation, limiting chances of in-depth exploration of identity alternatives and fostering a not adaptive, ruminative form of exploration, 
characterized by a tendency to mull over possible choices without being able to fully commit to any of them. Indeed, after a slight decrease in reconsideration of commitment from 14 to 15 years old, high-risk girls displayed a steep increase in reconsideration from 15 to 18 years old. It is suggested that reconsideration of commitment originates from a condition of dissatisfaction with current commitments and may stimulate identity change toward achievement of greater maturity. However, when reconsideration remains high, it is more likely to represent a maladaptive thinking and rethinking about the current situation that does not imply any true progress toward greater identity stability. This dark side of reconsideration of commitment has been captured in previous research revealing that reconsideration is associated with a diffuse identity style (Crocetti et al. 2009b), that is a style characterized by a tendency to procrastinate and delay dealing with identity issues as long as possible (Berzonsky 1989). This diffuse style also has been found to be related to several types of problem behaviors, including drug and alcohol problems (cf. Berzonsky 2004).

Finally, in our study, the differentiation between adolescents who run a low-risk versus a high-risk for externalizing problem behavior adolescents was based on teacher reports at early adolescence. We can draw two conclusions from this. First, teacher reports effectively predicted difficulties in identity formation over the course of middle to late adolescence. Second, we can exclude the possibility that differences in identity are due to a sort of Pygmalion effect (Rosenthal and Jacobson 1992), according to which students would be influenced by their teachers' expectations. Indeed, the students were evaluated by their teachers before transitioning to secondary school with new teachers. This transition provided students with the opportunity to start anew and reinvent themselves in a new context, without the potential burden of previous teachers' expectations. Nonetheless, we cannot completely exclude the possibility that students with a longer history of externalizing problem behaviors performed in the schoolsystem had internalized a set of teacher expectations that might continue to influence them even in a new different school environment. This is a potential shortcoming that needs to be addressed in future studies.

\section{Strengths and Limitations of this Study}

and Suggestions for Future Research

This study should be considered both in light of its strengths and shortcomings that might suggest future lines of research. First, in respect to the strengths of this study, this investigation utilized a five-wave longitudinal design that covered ages 14 until 18. As widely advocated (e.g., Schwartz 2005), longitudinal designs are necessary to capture adolescent identity trajectories. However, a potential shortcoming is the one-year interval between assessments. It might be that longitudinal designs that use multiple waves with shorter intervals among them (e.g., monthly intervals) could unravel in more detail the identity trajectories of adolescents with different risks of externalizing problem behaviors.

Second, we predicted identity formation in middle and late adolescence from early adolescence risk status based on teacher-rated externalizing problems. Although teachers' ratings can be affected by various biases related to teachers' expectations and/or student reputation, a wide corpus of evidence has revealed that the TRF is reliable tool for assessing externalizing problem behaviors (see Ivanova et al. 2007, for a test of TRF validity in 20 societies). In addition, Verhulst et al. (1994) found that the teachers' reports were strong predictors of following adolescents' development. Teachers' reports predicted poor outcomes equally well or even somewhat better than parents' reports, leading Verhulst et al. (1994; p. 543) to conclude that "it is therefore important to include teacher information in the diagnostic assessment of children". Findings of the current study further support this consideration, showing that teachers' reports of externalizing problems predicted later differences in adolescent identity development.

Third, given the limited literature on identity and externalizing problem behaviors, it was important to focus on externalizing problem behaviors as a whole in the present study. Since this study has demonstrated that adolescents with different risks of externalizing problem behaviors also differ in their identity paths it would be meaningful to continue this line of research with problem behaviors that first occur in adolescence (e.g., binge drinking and substance use). In other words, it would be very interesting to uncover identity trajectories specific to various types of problem behaviors, in order to refine prevention interventions.

Fourth, a further strength of this study is that it examined for the first time identity development in adolescents who were classified to be at low-risk versus a high-risk for externalizing problem behaviors. However, we were not able to control for possible differences in early identity formation, as we had no assessments on identity at the age of 12. Since identity formation is an ongoing process, especially in middle and late adolescence, the impact of this omission is uncertain.

Fifth, an additional strength of the current study is its focus on gender effects. In fact, we analyzed identity trajectories in both boys and girls with a low-risk versus a high-risk for externalizing problems that uncovered some interesting gender specificities. However, in our study, ethnic differences were not taken into account, as we 
focused exclusively on Dutch adolescents. Future research might improve our understanding of this topic by examining identity paths in adolescents from different ethnic groups with varying risk levels of externalizing problem behaviors.

Related to the previous point, there is also another issue that could be improved in future research. In the current study, we assessed global identity considering identity domains relevant to all adolescents (i.e., for the ideological domain we assessed educational identity and for the relational domain we focused on friendship). Future studies could expand this line of research by considering ethnic identity as well, even though this is not as salient for the majority group (e.g., Caucasian adolescents living in the USA) as it is for the minority groups (e.g., African-American or Hispanic adolescents living in the USA; Branch et al. 2000). Up to now, studies on ethnic identity and externalizing problem behaviors have yielded inconsistent findings, with some research reporting significant associations (e.g., McMahon and Watts 2002; Shrake and Rhee 2004), but not being confirmed by other investigations (e.g., Schwartz et al. 2007, 2009). Even within the same study, associations between externalizing problems and identity are sometimes found only for some ethnic groups, but not for others. For instance, Wissink et al. (2008) found that ethnic identity commitment was related significantly to externalizing problem behaviors only among Moroccan-Dutch adolescents, whereas this link was not found to be significant among either Turkish-Dutch nor native Dutch adolescents. Therefore, future research could shed more light on this issue by paying attention to group-specific ethno-cultural experiences (Gray-Little and Hafdahl 2000) and analysing different moderating factors that could account for the diverging findings reported in the literature.

\section{Practical Implications}

The present study has several practical implications. We have found that early adolescents with a high risk of externalizing problem behaviors have greater difficulties in developing a coherent sense of identity over the course of adolescence. Thus, early externalizing problem behaviors, just like internalizing problems (Crocetti et al. 2009a), might hamper identity formation. These results, together with those documenting that a condition of identity confusion is related to increasing problem behaviors (e.g., Meeus et al. 2012), point to the reciprocal relationships between externalizing problem behaviors and identity. In other words, adolescents who run a high-risk for problem behaviors find it difficult to achieve a stable identity and a lack of a firm sense of identity fosters higher rates of problem behaviors, contributing to the development of a negative spiral.
Therefore, it is of utmost importance to intervene promptly in order to prevent a negative spiral and reduce the probability that youth with problem behaviors become life-course persistent deviant adults (Moffitt 1993). In this respect, the results of this study highlight that teacher reports can be fruitful for identifying adolescents that run a high-risk of externalizing problem behaviors. Thus, teacher reports (Achenbach 1991) are a valuable tool for conducting early screenings aimed at identifying adolescents who could benefit from tailored interventions.

Interventions might be applied at different levels, focused both at reducing externalizing problem behaviors as well as supporting identity formation (Schwartz and Pantin 2006). A key ingredient of interventions could be the quality of family relationships. In fact, both the occurrence of externalizing problem behaviors (e.g., Williams et al. 2009) and the achievement of identity maturity (e.g., Kroger and Marcia 2011) are intertwined with family relationships. In regard to specific interventions, in a recent study by Wijsbroek et al. (2010), it was suggested that Parent Management Training may be one of the better inventions. This training is a well-documented and evaluated treatment for delinquency symptoms of early adolescents (e.g., Brestan and Eyberg 1998; Hipwell and Loeber 2006; Kazdin 2000) and also helps to improve the quality of positive parenting skills (Nock 2003). Specifically, Parent Management Training is a behavioral therapy that emphasizes social learning principles (Kazdin 2005). While it falls outside of the scope of the present study, it is conceivable that this training could be modified to address adolescent identity formation issues. Since the techniques applied in this training are based on behavioral theory (such as reinforcement principles), a modified version of the Parent Management Training that also addresses adolescent identity formation issues could be employed not only in individual or group therapies, but also as a schoolbased prevention programs. The findings of this study would suggest that exploring into such therapies and prevention programs merits future research attention.

\section{Conclusion}

The present study shed light on identity paths of early adolescents with a low-risk versus a high-risk of externalizing problem behaviors. We found that boys and girls with a high-risk of externalizing symptoms reported more difficulties in developing a firm sense of identity over middle to late adolescence. Because externalizing problems behaviors and an incoherent sense of identity might reinforce each other in a negative spiral, it seems necessary to intervene promptly on the high-risk adolescents in order to promote positive youth development. 
Acknowledgments Elisabetta Crocetti is a Marie Curie fellow at the Utrecht University. In this article, data from the RADAR study were used. RADAR has been financially supported by the Netherlands Organization for Scientific Research (GB-MAGW 480-03-005), the Achmea Foundation for Victims and Society (Stichting Achmea Slachtoffer en Samenleving: SASS), and various other grants from the Netherlands Organization for Scientific Research (NWO), the VU University Amsterdam and Utrecht University.

Author contributions EC and WM conceived the current study; EC performed the statistical analyses and wrote the manuscript; TK participated in the data analysis and interpretation of the results; WWH participated in the interpretation of the results and in the drafting of the article; $\mathrm{HK}$ and WM are the principal investigators of the RADAR project and are responsible for the data collection. All authors read and approved the final manuscript.

\section{References}

Achenbach, T. M. (1966). The classification of children's psychiatric symptoms: A factor-analytic study. Psychological Monographs, 80, 1-37.

Achenbach, T. M. (1978). Psychopathology of childhood: Research problems and issues. Journal of Consulting and Clinical Psychology, 46, 759-776.

Achenbach, T. M. (1991). Manual for the youth self-report and 1991 profiles. Burlington: Department of Psychiatry, University of Vermont.

Achenbach, T. M., \& Edelbrock, C. S. (1978). The classification of child psychopathology: A review and analysis of empirical efforts. Psychological Bulletin, 85, 1275-1301.

Baumeister, R. F., \& Muraven, M. (1996). Identity as adaptation to social, cultural, and historical context. Journal of Adolescence, 19, 405-416.

Berzonsky, M. D. (1989). Identity style: Conceptualization and measurement. Journal of Adolescent Research, 4, 268-282.

Berzonsky, M. D. (2004). Identity processing style, self-construction, and personal epistemic assumptions: A social-cognitive perspective. European Journal of Developmental Psychology, 1, 303-315.

Bishop, D. I., Macy-Lewis, J. A., Schnekloth, C. A., Puswella, S., \& Struessel, G. L. (1997). Ego identity status and reported alcohol consumption: A study of first-year college students. Journal of Adolescence, 20, 209-218.

Block, J. (1971). Lives through time. Berkeley, CA: Bancroft Books.

Block, J., \& Robins, R. W. (1993). A longitudinal study of consistency and change in self-esteem from early adolescence to early adulthood. Child Development, 64, 909-923.

Bongers, I. L., Koot, H. M., van der Ende, J., \& Verhulst, F. C. (2003). The normative development of child and adolescent problem behavior. Journal of Abnormal Psychology, 112, 179-192.

Bosma, H. A. (1985). Identity development in adolescents: Coping with commitments. Unpublished doctoral dissertation, University of Groningen, The Netherlands.

Branch, C. W., Tayal, P., \& Triplett, C. (2000). The relationship of ethnic identity and ego identity status among adolescents and young adults. International Journal of Intercultural Relations, 24, 777-790

Brestan, E., \& Eyberg, S. (1998). Effective psychosocial treatment of conducted disordered children and adolescents: 29 years, 82 studies and 5,272 kids. Journal of Clinical Child Psychology, 27, 180-189.
Broidy, L. M., Nagin, D. S., Tremblay, R. E., Bates, J. E., Brame, B., Dodge, K. A., et al. (2003). Developmental trajectories of childhood disruptive behaviors and adolescent delinquency: A six-site, crossnational study. Developmental Psychology, 39, 222-245.

Browne, M. W., \& Cudeck, R. (1993). Alternative ways of assessing model fit. In K. A. Bollen \& J. S. Long (Eds.), Testing structural equation models (pp. 136-162). Beverly Hills: Sage.

Buist, K. L., Dekovíc, M., Meeus, W., \& van Aken, M. A. G. (2004). The reciprocal relationship between early adolescent attachment and internalizing and externalizing problem behaviour. Journal of Adolescence, 27, 251-266.

Buist, K. L., Deković, M., \& Prinzie, P. (2013). Sibling relationship quality and psychopathology of children and adolescents: A meta-analysis. Clinical Psychology Review, 33, 97-106.

Cheung, G. W., \& Rensvold, R. B. (2002). Evaluating goodness-of-fit indexes for testing measurement invariance. Structural Equation Modeling, 9, 233-255

Crocetti, E., Klimstra, T., Keijsers, L., Hale, W. W, I. I. I., \& Meeus, W. (2009a). Anxiety trajectories and identity development in adolescence: A five-wave longitudinal study. Journal of Youth and Adolescence, 38, 839-849.

Crocetti, E., Rubini, M., Berzonsky, M. D., \& Meeus, W. (2009b). Brief report: The Identity Style Inventory: Validation in Italian adolescents and college students. Journal of Adolescence, 32, 425-433.

Crocetti, E., Rubini, M., Luyckx, K., \& Meeus, W. (2008a). Identity formation in early and middle adolescents from various ethnic groups: From three dimensions to five statuses. Journal of Youth and Adolescence, 37, 983-996.

Crocetti, E., Rubini, M., \& Meeus, W. (2008b). Capturing the dynamics of identity formation in various ethnic groups: Development and validation of a three-dimensional model. Journal of Adolescence, 31, 207-222.

Crocetti, E., Schwartz, S. J., Fermani, A., \& Meeus, W. (2010). The Utrecht-Management of Identity Commitments Scale (U-MICS): Italian validation and cross-national comparisons. European Journal of Psychological Assessment, 26, 172-186.

Crocetti, E., Scrignaro, M., Sica, L. S., \& Magrin, M. E. (2012). Correlates of identity configurations: Three studies with adolescent and emerging adult cohorts. Journal of Youth and Adolescence, $41,732-748$.

Dodge, K. A., Lansford, J. E., Burks, V. S., Bates, J. E., Pettit, G. S., Fontaine, R., et al. (2003). Peer rejection and social informationprocessing factors in the development of aggressive behavior problems in children. Child Development, 74, 374-393.

Duncan, T. E., Duncan, S. C., Stryker, L. A., Li, F., \& Alpert, A. (1999). An introduction to latent variable growth curve modelling. Mahwah, NJ: Erlbaum.

Erikson, E. (1950). Childhood and society. New York: Norton.

Erikson, E. (1968). Identity, youth and crisis. New York: Norton.

Frank, S. J., Jacobson, S., \& Tuer, M. (1990). Psychological predictors of young adults' drinking behaviors. Journal of Personality and Social Psychology, 59, 770-780.

Gray-Little, B., \& Hafdahl, A. R. (2000). Factors influencing racial comparisons of self-esteem: A quantitative review. Psychological Bulletin, 126, 26-49.

Hinshaw, S. P. (1992). Externalizing behavior problems and academic underachievement in childhood and adolescence: Causal relationships and underlying mechanisms. Psychological Bulletin, $111,127-155$.

Hipwell, A. E., \& Loeber, R. (2006). Do we know which interventions are effective for disruptive and delinquent girls? Clinical Child and Family Psychology Review, 9, 221-255.

$\mathrm{Hu}, \mathrm{L}$. ., \& Bentler, P. M. (1999). Cut-off criteria for fit indexes in covariance structure analysis: Conventional criteria versus new alternatives. Structural Equation Modeling, 6, 1-55. 
Ivanova, M. Y., Achenbach, T. M., Rescorla, L. A., Dumenci, L., Almqvist, F., Bathiche, M., et al. (2007). Testing the teacher's report form syndromes in 20 societies. School Psychology Review, 36, 468-483.

Jones, R. M., \& Hartmann, B. R. (1988). Ego identity: Developmental differences and experimental substance use among adolescents. Journal of Adolescence, 11, 347-360.

Jones, R. M., Hartmann, B. R., Grochowski, C. O., \& Glider, P. (1989). Ego identity and substance abuse: A comparison of adolescents in residential treatment with adolescents in school. Personality and Individual Differences, 10, 625-631.

Kazdin, A. (2000). Perceived barriers to treatment participation and treatment acceptability among antisocial children and their families. Journal of Child and Family Studies, 9, 157-174.

Kazdin, A. E. (2005). Parent management training: Treatment for oppositional, aggressive, and antisocial behavior in children and adolescents. New York: Oxford University Press.

Kim, J. E., Hetherington, E. M., \& Reiss, D. (1999). Associations among family relationships, antisocial peers, and adolescents' externalizing behaviors: Gender and family type differences. Child Development, 70(5), 1209-1230.

Klimstra, T., Crocetti, E., Hale, W. W, I. I. I., Kolman, A., Fortanier, E., \& Meeus, W. (2011). Identity formation in juvenile delinquents and clinically referred youth. Revue Europeene De Psychologie Appliquee, 61, 123-130.

Klimstra, T., Hale, W. W, I. I. I., Raaijmakers, Q., Branje, S., \& Meeus, W. (2009). Maturation of personality in adolescence. Journal of Personality and Social Psychology, 96, 898-912.

Klimstra, T., Hale, W. W, I. I. I., Raaijmakers, Q., Branje, S., \& Meeus, W. (2010). Identity formation in adolescence: Change or stability? Journal of Youth and Adolescence, 39, 150-162.

Kline, R. B. (2011). Principles and practice of structural equation modelling (3rd ed.). New York: Guilford Press.

Kroger, J., \& Marcia, J. E. (2011). The identity statuses: Origins, meanings, and interpretations. In S. J. Schwartz, K. Luyckx, \& V. L. Vignoles (Eds.), Handbook of identity theory and research (pp. 31-53). New York: Springer.

Little, R. J. A. (1988). A test of missing completely at random for multivariate data with missing values. Journal of the American Statistical Association, 83, 1198-1202.

Luyckx, K., Goossens, L., \& Soenens, B. (2006). A developmental contextual perspective on identity construction in emerging adulthood: Change dynamics in commitment formation and commitment evaluation. Developmental Psychology, 42, 366380 .

Marcia, J. E. (1966). Development and validation of ego-identity status. Journal of Personality and Social Psychology, 3, 551-558.

McMahon, S. D., \& Watts, R. J. (2002). Ethnic identity in urban African American youth: Exploring links with self-worth, aggression, and other psychosocial variables. Journal of Community Psychology, 30, 411-431.

Meeus, W. (1996). Studies on identity development in adolescence: An overview of research and some new data. Journal of Youth and Adolescence, 25, 569-598.

Meeus, W. (2011). The study of adolescent identity formation 2000-2010: A review of longitudinal research. Journal of Research on Adolescence, 21, 75-94.

Meeus, W., Iedema, J., Helsen, M., \& Vollebergh, W. (1999). Patterns of adolescent identity development: Review of literature and longitudinal analysis. Developmental Review, 19, 419-461.

Meeus, W., Iedema, J., \& Maassen, G. H. (2002). Commitment and exploration as mechanisms of identity formation. Psychological Reports, 90, 771-785.

Meeus, W., van de Schoot, R., Keijsers, L., \& Branje, S. (2012). Identity statuses as developmental trajectories: A five-wave longitudinal study in early-to-middle and middle-to-late adolescents. Journal of Youth and Adolescence, 41, 1008-1021.

Meeus, W., van de Schoot, R., Keijsers, L., Schwartz, S. J., \& Branje, S. (2010). On the progression and stability of adolescent identity formation. A five-wave longitudinal study in early-to-middle and middle-to-late adolescence. Child Development, 81, 1565-1581.

Miller, S., Malone, P. S., \& Dodge, K. A. (2010). Developmental trajectories of boys' and girls' delinquency: Sex differences and links to later adolescent outcomes. Journal of Abnormal Child Psychology, 38, 1021-1032.

Moffitt, T. E. (1993). Adolescence-limited and life-course-persistent antisocial behavior: A developmental taxonomy. Psychological Review, 100, 674-701.

Muthén, L. K., \& Muthén, B. O. (2006). Mplus user's guide (4th ed.). Los Angeles, CA: Muthén \& Muthén.

Nelson, L. J., Padilla-Walker, L. M., \& Carroll, J. S. (2010). "I believe it is wrong but I still do it": A comparison of religious young men who do versus do not use pornography. Psychology of Religion and Spirituality, 2, 136-147.

Nock, M. K. (2003). Progress review of the psychosocial treatment of child conduct problems. Clinical Psychology: Science \& Practice, 10, 1-28.

Odgers, C. L., Moffitt, T. E., Broadbent, J. M., Dickson, N., Hancox, R. J., Harrington, H., et al. (2008). Female and male antisocial trajectories: From childhood origins to adult outcomes. Development and Psychopathology, 20, 673-716.

Oyserman, D., \& Destin, M. (2010). Identity-based motivation: Implications for intervention. Counseling Psychologist, 38, 1001-1043.

Pace, U., \& Zappulla, C. (2011). Problem behaviors in adolescence: The opposite role played by insecure attachment and commitment strength. Journal of Child and Family Studies, 20, $854-862$.

Reef, J., Diamantopoulou, S., Van Meurs, I., Verhulst, F. C., \& Van Der Ende, J. (2011). Developmental trajectories of child to adolescent externalizing behavior and adult DSM-IV disorder: Results of a 24-year longitudinal study. Social Psychiatry and Psychiatric Epidemiology, 46, 1233-1241.

Rescorla, L., Achenbach, T. M., Ivanova, M. Y., Dumenci, L., Almqvist, F., Bilenberg, N., et al. (2007). Epidemiological comparisons of problems and positive qualities reported by adolescents in 24 countries. Journal of Consulting and Clinical Psychology, 75, 351-358.

Roberts, B. W., Caspi, A., \& Moffitt, T. E. (2001). The kids are alright: Growth and stability in personality development from adolescence to adulthood. Journal of Personality and Social Psychology, 81, 670-683.

Rosenthal, R., \& Jacobson, L. (1992). Pygmalion in the classroom. New York: Irvington.

Satorra, A., \& Bentler, P. M. (1994). Corrections to test statistics and standard errors in covariance structure analysis. In A. Von Eye \& C. C. Clogg (Eds.), Latent variables analysis: Applications for developmental research (pp. 399-419). Thousand Oaks, CA: Sage.

Satorra, A., \& Bentler, P. M. (2001). A scaled difference Chi square test statistic for moment structure analysis. Psychometrika, 66, 507-514.

Schwartz, B. (2000). Self-determination: The tyranny of freedom. American Psychologist, 55, 79-88.

Schwartz, S. J. (2001). The evolution of Eriksonian and, neoEriksonian identity theory and research: A review and integration. Identity: An International Journal of Theory and Research, $1,7-58$.

Schwartz, S. J. (2005). A new identity for identity research: Recommendations for expanding and refocusing the identity literature. Journal of Adolescent Research, 20, 293-308. 
Schwartz, S. J., Forthun, L. F., Ravert, R. D., Zamboanga, B. L., Umaña-Taylor, A. J., Filton, B. J., et al. (2010). Identity consolidation and health risk behaviors in college students. American Journal of Health Behavior, 34, 214-224.

Schwartz, S. J., \& Pantin, H. (2006). Identity development in adolescence and emerging adulthood: The interface of self, context, and culture. In A. Prescott (Ed.), The concept of self in psychology (pp. 45-85). Hauppage, NY: Nova Science Publishers.

Schwartz, S. J., Zamboanga, B. L., \& Jarvis, L. H. (2007). Ethnic identity and acculturation in Hispanic early adolescents: Mediated relationships to academic grades, prosocial behaviors, and externalizing symptoms. Cultural Diversity and Ethnic Minority Psychology, 13, 364-373.

Schwartz, S. J., Zamboanga, B. L., Weisskirch, R. S., \& Rodriguez, L. (2009). The relationships of personal and ethnic identity exploration to indices of adaptive and maladaptive psychosocial functioning. International Journal of Behavioral Development, $33,131-144$

Shrake, E. K., \& Rhee, S. (2004). Ethnic identity as a predictor of problem behaviors among Korean American adolescents. Adolescence, 39, 601-622.

Simonoff, E., Elander, J., Holmshaw, J., Pickles, A., Murray, R., \& Rutter, M. (2004). Predictors of antisocial personality: Continuities from childhood to adult life. British Journal of Psychiatry, $184,118-127$.

Sturaro, C., van Lier, P. A. C., Cuijpers, P., \& Koot, H. M. (2011). The role of peer relationships in the development of early school-age externalizing problems. Child Development, 82, $758-765$.

van Lier, P. A. C., Frijns, T., den Exter Blokland, E., Neumann, A., Koot, H. M., \& Meeus, W. (2008). The RADAR study: Design, description of sample and validation of cohort assignment (unpublished manuscript).

Vandenberg, R. J., \& Lance, C. E. (2000). A review and synthesis of the measurement invariance literature: Suggestions, practices, and recommendations for organizational research. Organizational Research Methods, 3, 4-69.

Verhulst, F. C., J. Van der Ende, \& J. M. Koot (1997). Handleiding voor de Teacher's Report Form. [Manual for the Teacher's Report Form]. Rotterdam: Afdeling Kinder- en Jeugdpsychiatrie, Sophia Kinderziekenhuis/Academisch Ziekenhuis Rotterdam/ Erasmus Universiteit Rotterdam.

Verhulst, F. C., Koot, H. M., \& Van der Ende, J. (1994). Differential predictive value of parents' and teachers' reports of children's problem behaviors: A longitudinal study. Journal of Abnormal Child Psychology, 22, 531-546.

Wijsbroek, S. A. M., Hale, W. W, I. I. I., Raaijmakers, Q. A. W., \& Meeus, W. H. J. (2010). Is the resolution style 'exiting statements' in parent-adolescent conflicts related to adolescent internalizing and externalizing problem behavior? Journal of Applied Developmental Psychology, 31, 60-69.
Williams, L. R., Degnan, K. A., Perez-Edgar, K. E., Henderson, H. A., Rubin, K. H., Pine, D. S., et al. (2009). Impact of behavioral inhibition and parenting style on internalizing and externalizing problems from early childhood through adolescence. Journal of Abnormal Child Psychology, 37, 1063-1075.

Wissink, I. B., Deković, M., Yağmur, S., Stams, G. J., \& de Haan, M. (2008). Ethnic identity, externalizing problem behaviour and the mediating role of self-esteem among Dutch, Turkish-Dutch and Moroccan-Dutch adolescents. Journal of Adolescence, 31, 223-240.

Zoccolillo, M. (1992). Co-occurrence of conduct disorder and its adult outcomes with depressive and anxiety disorders: A review. Journal of the American Academy of Child and Adolescent Psychiatry, 31, 547-556.

\section{Author Biographies}

Elisabetta Crocetti is a Marie Curie post-doctoral researcher at the Research Centre on Adolescent Development, Utrecht University, The Netherlands. She received her doctorate in Educational Sciences from the University of Macerata, Italy. Her major research interests include identity formation in adolescence and emerging adulthood.

Theo A. Klimstra is Assistant Professor at Tilburg University, The Netherlands. He received his doctorate in Social Sciences from the Utrecht University, The Netherlands. His major research interests include personality, identity, and adolescent development.

William W. Hale III is Associate Professor at the Research Centre on Adolescent Development, Utrecht University, The Netherlands. He received his doctorate in Biological Psychiatry from the University of Groningen, The Netherlands. His major research interests include adolescent depression and anxiety, and the effects parental interactions have on these psychosocial problem behaviors.

Hans M. Koot is professor and director of Developmental Psychology and Developmental Psychopathology at VU University Amsterdam, The Netherlands. He received his doctorate from the Erasmus University, Rotterdam, The Netherlands. His major research interests regard the etiology, diagnostics, and intervention of emotional and behavioral problems in children and adolescents.

Wim Meeus is Professor of Adolescent Development at Utrecht University, and Professor of Developmental Psychology at Tilburg University, The Netherlands. He received his doctorate in Social Psychology from the Utrecht University, The Netherlands. His major research interests include identity and personality development, personal relationships, and psychosocial problems in adolescence. 